\title{
Differentiated Thyroid Carcinomas from Children and Adolescents Express IGF-I and the IGF-I Receptor (IGF-I-R). Cancers with the Most Intense IGF-I-R Expression May Be More Aggressive
}

\author{
HARKIRTIN GYDEE, J. TIMOTHY O’NEILL, ANEETA PATEL, ANDREW J. BAUER, \\ R. MICHAEL TUTTLE, AND GARY L. FRANCIS
}

Department of Pediatrics, Uniformed Services University of the Health Sciences, Bethesda, Maryland, 20814, U.S.A. [H.G., J.T.O., A.P., G.L.F.], Departments of Pediatrics and Clinical Investigation, Walter Reed Army Medical Center, Washington, D.C., 20307, U.S.A. [A.J.B.], Department of Endocrinology, Memorial Sloan Kettering Cancer Center, New York, New York, 10021, U.S.A. [R.M.T.]

ABSTRACT

\begin{abstract}
Adult thyroid cancers express IGF and IGF-I receptor (IGFI-R), but the clinical impact is not clear. No previous study examined any childhood thyroid cancers that are welldifferentiated and have a favorable prognosis. We used immunohistochemistry to determine IGF-I and IGF-I-R in 23 papillary thyroid cancers (PTC) and 6 follicular thyroid cancers (FTC) from children and adolescents. IGF-I was detected in $45 \%$ and IGF-I-R in $43 \%$ of cancers. IGF-I and IGF-I-R were found more often in PTC (IGF-I $=9 / 23$, IGF-I-R $=8 / 19$ ) than normal surrounding thyroid (IGF-I $=0 / 10, p=0.032$ and IGF-I-R $=$ $0 / 10, p=0.030)$. There were too few FTC to support independent statistical analysis, but IGF-I was found in 4 of 6 FTC $(0 / 10$ normal), and IGF-I-R was found in 2 of 4 FTC (0/10 normal). IGF-I-R staining was more intense in aggressive (invasive, metastatic, recurrent, or persistent) than indolent tumors (confined to the gland, $p=0.029)$. Over time, six tumors recurred, five of which expressed IGF-I-R. Overall recurrence risk was significantly greater for tumors that expressed IGF-I-R $(p=0.05)$ but only approached statistical significance $(p=0.08)$ when disease-
\end{abstract}

free survival was determined. We conclude that differentiated thyroid cancers of children and adolescents express IGF-I and IGF-I-R. Tumors that express IGF-I-R are more likely to show aggressive clinical features (invasion beyond the capsule, metastasis, or recurrence) and persistence despite treatment. (Pediatr Res 55: 709-715, 2004)
Abbreviations
IGF-I-R, insulin-like growth factor receptor I
IR, insulin receptor
ACTUR, automated central tumor registry size
Tg, thyroglobulin
FTC, follicular thyroid cancer
PTC, papillary thyroid cancer
DAB, diaminobenzadine
VEGF, vascular endothelial growth factor

MACIS, metastasis, age, completeness of resection, invasion,
Increasing evidence suggests important roles for IGF and IGF-I-R in the growth and clinical behavior of many cancers, including those of breast, colon, and prostate. Toropainen et al.

Received April 15, 2003; accepted August 7, 2003.

Correspondence: Gary L. Francis, M.D., Ph.D., Department of Pediatrics, Uniformed Services University of the Health Sciences, 4301 Jones Bridge Rd., Bethesda, MD 20814, U.S.A.; e-mail: gfrancis@usuhs.mil

Support for this work was obtained from the Department of Clinical Investigation, Walter Reed Army Medical Center, Washington, DC.

The opinions or assertions contained herein are the private views of the authors and are not to be construed as official or to reflect the opinions of the Uniformed Services University of the Health Sciences, the United States Army, or the Department of Defense.

DOI: 10.1203/01.PDR.0000111282.98401.93
(1) showed that IGF-I was expressed by $91 \%$ of breast cancers and was more frequently observed in tumors with favorable indicators such as intraductal growth, distinct tumor margins, and a high probability of survival. IGF-I, IGF-II, and IGF-I-R have all been identified in colon cancers, where the expression of IGF-I-R appears to be related to poor prognostic indicators such as tumor growth, angiogenesis, and metastasis (2-5). Expression of IGF-II is increased in prostate cancers, where it may have a role in metastasis (6). Targeted mutagenesis of the IGF-I-R supports the hypothesis that IGF-I-R is critically important for transformation (7). Studies by Sell et al. (7) showed that interruption of IGF-I-R expression in malignant cells renders them unable to establish colonies in soft agar. 
During the last decade, thyroid cancers have also been shown to express IGF and IGF-I-R, but the clinical impact of expression is not entirely clear. IGF-I was expressed by $90 \%$ of adult PTC and in vitro studies have shown that IGF-I stimulates growth of PTC-derived cell cultures (8-10). However, expression of IGF-I had no prognostic significance for adults (8). IGF-I-R was expressed by the majority of adult thyroid cancers, and the expression of IGF-I-R was significantly correlated with tumor size (11). Larger tumor size has itself been associated with a higher risk of recurrence (12). However, Vella et al. (13-15) recently found that IGF-I-R were expressed only by differentiated thyroid cancers, whereas IR were expressed by poorly differentiated thyroid cancers. Their data would suggest that IGF-I-R might be found in tumors with more favorable prognosis (13-15). Unfortunately, none of these studies included any childhood thyroid cancers, which are generally well-differentiated and have a favorable prognosis (16).

The goal of our study was to examine the expression of IGF-I and IGF-I-R in differentiated thyroid cancers from children and adolescents and to correlate expression with tumor growth, metastasis, and recurrence. Our data show that the intensity of IGF-I and IGF-I-R expression is increased in childhood thyroid cancers compared with normal surrounding tissue, and that more aggressive cancers have more intense expression of IGF-I-R.

\section{METHODS}

Approval. This study received prior approval and funding (WU\# 02-65001e) from the Human Use Committee of the Department of Clinical Investigation, Walter Reed Army Medical Center, Washington, DC. This was a retrospective study of previously existing tissue samples from which all patient identifiers had been removed, allowing the study to be approved as an exempt protocol without prior consent.

Patients. We searched the automated centralized tumor registry of the Department of Defense (ACTUR) to identify all patients who were $\leq 21$ y of age when diagnosed with thyroid cancer. Original medical records were used to construct a database that includes demographic features, tumor characteristics, treatment, and clinical outcome (16). The extent of disease at diagnosis was classified according to the system of DeGroot et al. (12). According to DeGroot et al., class 1 disease is confined to the thyroid gland, class 2 involves the regional lymph nodes, class 3 either extends beyond the capsule or was inadequately resected, and class 4 has distant metastasis (lung or bone). In addition, we used the MACIS scoring system for comparisons (17). According to the MACIS system, the following formula is used to calculate MACIS scores for all patients $<39$ y of age: MACIS $=3.1+$ (size $\times$ $0.3)+1$ (if incomplete resection) +1 (if invasive beyond the capsule) +3 (if distant metastasis). As in our previous studies, recurrence was defined as the appearance of new disease (identified by radioactive iodine scan or biopsy) in any patient who had been free of disease (no disease palpable or identified by radioactive iodine scan) for a period of 4 mo after initial therapy (16).
The majority of patients received their medical care before the routine use of serum $\mathrm{Tg}$ levels for defining recurrence-free survival. For this reason, Tg levels are not used in our definitions, however, Tg levels were determined for contemporary patients (normal, 3-40 ng/mL; University of Southern California Clinical Laboratories, Los Angeles, CA, U.S.A.). The clinical details of these and other patients have been previously published by our group (16).

Immunohistochemistry. Sufficient formalin-fixed, paraffinembedded archival tumor tissue was available to stain 23 PTC and 6 FTC for the expression of IGF-I and IGF-I-R. Formalinfixed, paraffin-embedded tissue blocks were sectioned and stained with hematoxylin and eosin to confirm the diagnosis (18). Sections immediately adjacent $(5 \mu \mathrm{m})$ were used for immunohistochemistry. Sections were deparaffinized with xylene and rehydrated through a series of graded alcohol solutions and nuclease-free water. Endogenous peroxidase was quenched $\left(3 \% \mathrm{H}_{2} \mathrm{O}_{2}, 30 \mathrm{~min}\right.$, room temperature), after which, IGF-I-R antigen retrieval was performed with protease (30 min, Ventana Medical Systems, Tucson, AZ, U.S.A.). Antigen retrieval was not required for IGF-I staining. Sections were incubated with either primary anti-IGF-I (1:100, Upstate Biotechnology, Lake Placid, NY, U.S.A.), or anti-IGF-I-R (1:100, Upstate Biotechnology), and secondary biotinylated anti-IgG. Four sections from each tumor were stained on the Ventana NEXES automated slide stainer (Ventana Medical Systems) using the universal DAB detection (IGF-I and IGF-I-R) and amplification (IGF-I-R only) kits. The presence and intensity of IGF-I and IGF-I-R staining were determined by two blinded, independent examiners and quantified from absent (grade 0 ) in intense (grade 3 ) with $>90 \%$ concordance. None of the samples showed intense IGF-I-R expression, limiting the highest grade of IGF-I-R staining to moderate (grade 2). A third, independent examiner scored those samples in which there was disagreement, and the two scores in agreement were used as the final intensity score. Samples of human or porcine kidney were used as positive control for IGF-I and human placenta was used as positive control for IGF-I-R. Separate negative controls were performed in which PBS was substituted for the primary or secondary antibodies. Tissue sections $(n=10)$ from 10 patients were identified that contained sufficient normal thyroid tissue surrounding these tumors to determine the expression of IGF-I and IGF-I-R in what appears to be normal thyroid.

Data Analysis and Statistical Comparisons. The presence and intensity of IGF-I and IGF-I-R expression were correlated with the histologic variant, demographic features, size of the tumor, extent of disease at diagnosis, and clinical outcome. Statistical analyses were performed using SPSS for Windows 95 (Version 7.5, SPSS Inc., Chicago, IL, U.S.A.). The average intensity of staining was compared by ANOVA, and the proportion of tumors that stained for IGF-I or IGF-I-R were compared by Fisher's exact test. Correlations were performed using Pearson correlation, and recurrence-free survival was calculated using Kaplan-Meier survival curves with log-rank comparison. Unless otherwise indicated, data are presented as mean \pm SEM. 


\section{RESULTS}

The clinical features of the 29 patients are shown in Table 1. They ranged in age from 6 to $21 \mathrm{y}$ (mean $=16.4 \pm 4.3 \mathrm{y}$ ) and had tumors with an average size of $2.1 \pm 1.6 \mathrm{~cm}$ (range, $0.2-7.5 \mathrm{~cm}$ ). Among the patients with PTC, 12 had class 1 disease, 9 had class 2 disease, 1 had class 3 disease, and 1 had class 4 disease. The average MACIS score for the patients with PTC was $3.9 \pm 0.93$ (range, 3.25-7.39). Six patients had FTC, for which, DeGroot class and MACIS scores are not routinely performed $(12,17)$. The patients were followed for an average of $57 \pm 44$ mo (range, $0-169$ mo) after therapy. During that time, six developed recurrent disease (6-67 mo after initial therapy). The clinical details, treatment, and outcome for these
29 patients are similar to those of a larger cohort previously published by our group (16).

Staining for IGF-I and IGF-I-R was seen throughout the lesions with no apparent difference between the periphery and center (Fig. 1). Overall, IGF-I was detected in $45 \%$ of thyroid cancers, including $39 \%$ of PTC $(9 / 23)$ and 4 of 6 FTC. IGF-I-R was detected in $43 \%$ of thyroid tumors, including $42 \%$ of PTC $(8 / 19)$ and 2 of 4 FTC. In contrast, neither IGF-I nor IGF-I-R was detected in any sections of surrounding normal thyroid tissue from 10 of the patients. Expression of IGF-I and IGF-I-R was more common in PTC than normal tissue (IGF-I, $p=0.032$; IGF-I-R, $p=0.030$ by Fisher's Exact test). There were too few FTC to support independent statistical compari-

Table 1. Clinical features and expression of IGF-I and IGF-I-R by childhood thyroid cancers

\begin{tabular}{|c|c|c|c|c|c|c|c|c|c|c|c|}
\hline Case & $\begin{array}{l}\text { Age }(\mathrm{y}) / \\
\text { gender }\end{array}$ & $\begin{array}{c}\text { Tumor size } \\
(\mathrm{cm})\end{array}$ & $\begin{array}{c}\text { MACIS } \\
\text { score }^{1}\end{array}$ & $\begin{array}{l}\text { Unifocal/ } \\
\text { multifocal }\end{array}$ & $\begin{array}{l}\text { Thyroid } \\
\text { surgery }^{2}\end{array}$ & $\begin{array}{c}\text { Node } \\
\text { surgery }^{3}\end{array}$ & ${ }^{131} \mathrm{I}$ & $\begin{array}{c}\text { Follow-up } \\
\text { (mo) }\end{array}$ & $\begin{array}{c}\text { Recur } \\
\text { (mo) }\end{array}$ & IGF-I & IGF-I-R \\
\hline \multicolumn{12}{|c|}{ Papillary thyroid cancers } \\
\hline 1 & $14 / \mathrm{M}$ & 0.5 & 3.25 & Multi & Total & MR & $\mathrm{N}$ & 10 & & 0 & 0 \\
\hline 2 & $19 / \mathrm{F}$ & 0.7 & 3.31 & Uni & Sub & $\mathrm{S}$ & $\mathrm{Y}$ & 106 & & 3 & Unk \\
\hline 5 & $11 / \mathrm{F}$ & 1.5 & 3.55 & Uni & Sub & Unk & $\mathrm{N}$ & 18 & & 0 & 0 \\
\hline 6 & $16 / \mathrm{F}$ & 1.5 & 3.55 & Multi & Unk & Unk & Y & 19 & & 1 & 0 \\
\hline 7 & $21 / \mathrm{F}$ & 1.8 & 3.64 & Uni & Total & $\mathrm{S}$ & Unk & 68 & & 0 & 1 \\
\hline 8 & $14 / \mathrm{M}$ & 2.0 & 3.70 & Uni & Total & S & $\mathrm{Y}$ & 63 & 11 & 0 & 1 \\
\hline 9 & $21 / \mathrm{F}$ & 2.3 & 3.79 & Multi & Total & S & Unk & 18 & & 0 & 0 \\
\hline 10 & $17 / \mathrm{F}$ & 2.4 & 3.82 & Uni & Total & MR & $\mathrm{Y}$ & 50 & & 0 & 0 \\
\hline \multicolumn{12}{|c|}{ Class $2^{4}$} \\
\hline 13 & 19/M & 0.5 & 3.25 & Uni & Total & $\mathrm{S}$ & $\mathrm{Y}$ & 36 & & 0 & 0 \\
\hline 14 & $15 / F$ & 0.7 & 3.31 & Multi & Total & MR & $\mathrm{Y}$ & 85 & & 0 & 1 \\
\hline 15 & $10 / F$ & 0.8 & 3.34 & Uni & Total & MR & Y & 15 & & 2 & 0 \\
\hline 16 & $20 / \mathrm{F}$ & 1.0 & 3.4 & Uni & Total & MR & $\mathrm{Y}$ & 101 & & 0 & 1 \\
\hline 17 & $19 / \mathrm{M}$ & 1.0 & 3.4 & Multi & Unk & Unk & $\mathrm{N}$ & 104 & & 1 & 2 \\
\hline 18 & $21 / \mathrm{F}$ & 1.0 & 3.4 & Multi & Total & S & $\mathrm{N}$ & 22 & & 0 & 0 \\
\hline 19 & $14 / F$ & 3.0 & 4.0 & Multi & Total & MR & $\mathrm{Y}$ & 86 & 67 & 0 & 1 \\
\hline 20 & $13 / \mathrm{F}$ & 5.5 & 4.75 & Multi & Sub & Unk & $\mathrm{N}$ & 0 & & 3 & Unk \\
\hline 21 & $15 / \mathrm{F}$ & 7.5 & 5.35 & Multi & Total & MR & Y & 27 & & 0 & 0 \\
\hline \multicolumn{12}{|c|}{ Class $3^{4}$} \\
\hline 22 & $19 / \mathrm{F}$ & 2.0 & 4.7 & Multi & Total & MR & $\mathrm{Y}$ & 86 & 17 & 2 & 1 \\
\hline 27 & $19 / \mathrm{F}$ & 2.8 & & Uni & Total & Sub & $\mathrm{N}$ & 18 & & 1 & Unk \\
\hline 28 & Unk & Unk & & Unk & Unk & Unk & Unk & Unk & & 3 & Unk \\
\hline 29 & Unk & Unk & & Unk & Unk & Unk & Unk & Unk & & 0 & 0 \\
\hline
\end{tabular}

${ }^{1}$ MACIS score according to Hay et al. 17.

${ }^{2}$ Thyroid surgery includes any procedures labelled "completion thyroidectomy." Total, total thyroidectomy; Sub, subtotal thyroidectomy; Unk, unknown.

${ }^{3}$ Node surgery categorized as S, removal of suspicious nodes; MR, modified radical neck dissection; Unk, unknown.

${ }^{4}$ Class according to DeGroot et al. 12 .

${ }^{5}$ Follicular thyroid cancers are not classified according to DeGroot 12 or MACIS 17. 


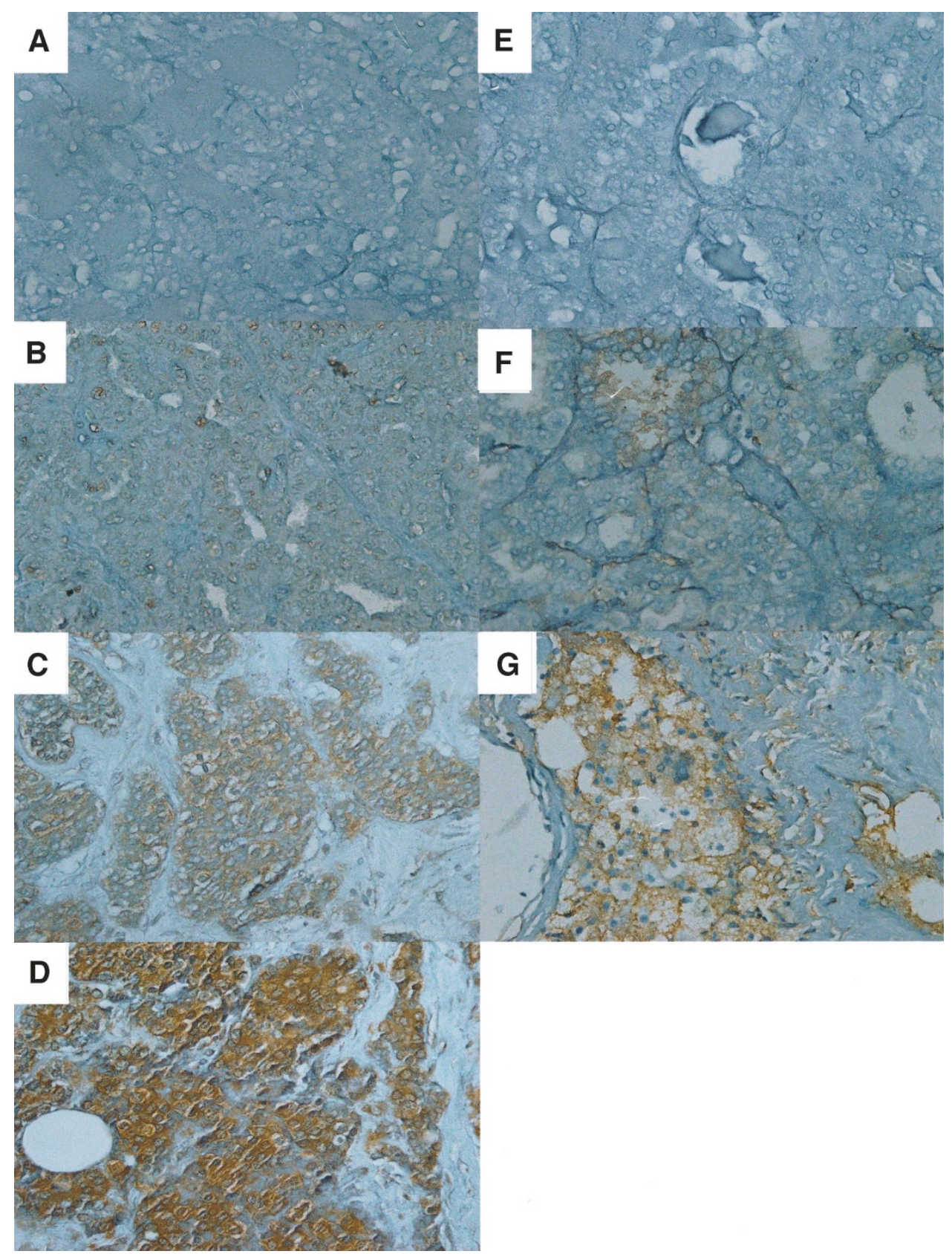

Figure 1. Representative Staining for IGF-I and IGF-I-R. Specific staining for IGF-I was quantified as absent $(A$, grade 0$)$, mild $(B$, grade 1$)$, moderate $(C$, grade 2 ), or intense $(D$, grade 3$)$. Specific staining for IGF-I-R was quantified as absent ( $E$, grade 0$)$, mild ( $F$, grade 1$)$, or moderate $(G$, grade 2 ).

sons, but IGF-I was found in 4 of 6 FTC $(0 / 10$ normal $)$ and IGF-I-R was found in 2 of 4 FTC (0/10 normal).

There was no difference in the intensity of IGF-I and IGF$\mathrm{I}-\mathrm{R}$ expression between PTC (IGF-I $=0.74 \pm 0.24$ and IGF-I-R $=0.47 \pm 0.14)$ and FTC (IGF-I $=1.3 \pm 0.56, p=$ 0.28 ; and IGF-I-R $=0.5 \pm 0.29, p=0.94)$. There was also no difference in IGF-I expression between aggressive tumors (invasive, metastatic, recurrent, or persistent, IGF-I $=0.8 \pm 0.49$ ) and indolent tumors (confined to the gland, IGF-I $=0.72 \pm$ $0.28, p=0.90$ ). However, as shown in Figure 2, the intensity of IGF-I-R expression was significantly greater among all aggressive tumors compared with indolent tumors (Fig. $2 \mathrm{~A}$, $p=0.029)$, and all aggressive PTC compared with indolent PTC (Fig. $2 B, p=0.029$ ).
Tumors were stratified according to the presence or absence of IGF-I expression (Table 2). Patient age, tumor size, MACIS score, treatment, and the length of follow-up were similar for tumors that either did or did not express IGF-I. Over time, six tumors recurred, half of which expressed IGF-I. Disease-free survival (Fig. 3) tended to be shorter for tumors that expressed IGF-I, but the difference was not significant $(p=0.17)$.

Tumors were also stratified according to the presence or absence of IGF-I-R expression (Table 3). Patient age, tumor size, MACIS score, and treatment were similar for tumors that either did or did not express IGF-I-R. The length of follow-up was approximately twice as long for tumors that expressed IGF-I-R, but the difference only approached statistical significance $(p=0.06)$. Over time, six tumors recurred, five of 


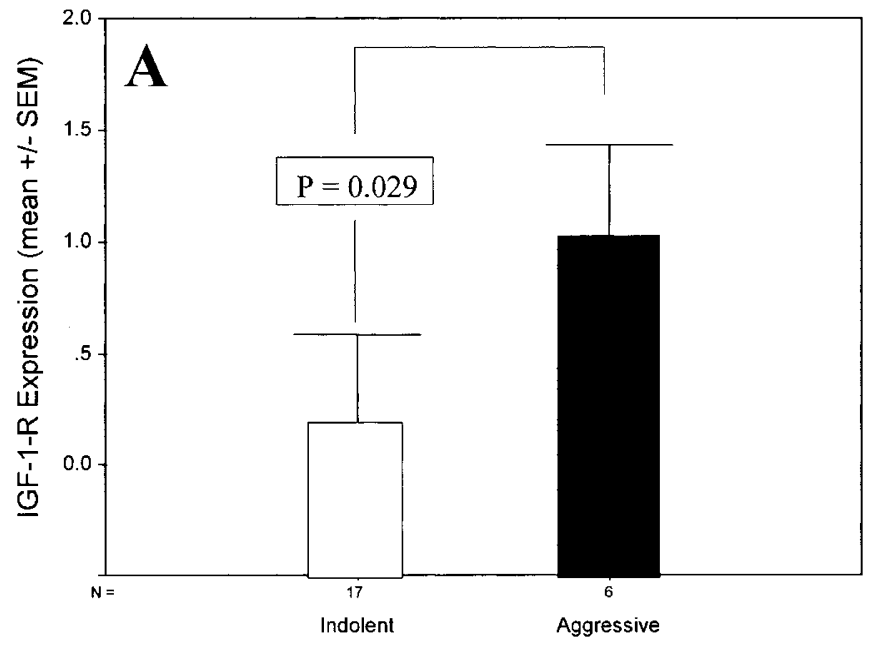

Clinical Behavior

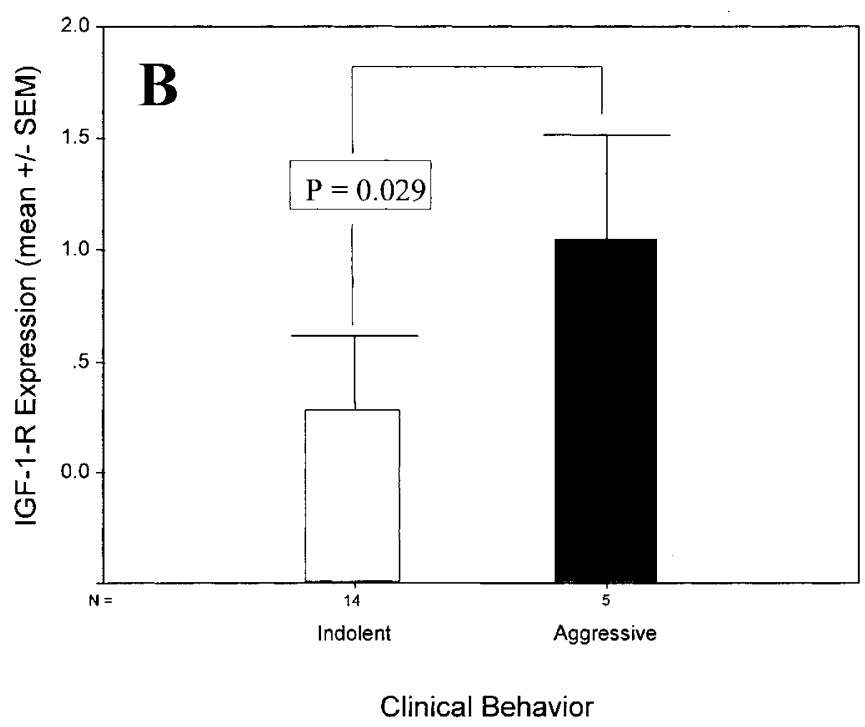

Figure 2. Comparison of IGF-I-R expression in indolent and aggressive thyroid cancers. $(A)$ All cancers were divided into those with aggressive features (invasion, metastasis, recurrence, and persistence) and those with indolent features (confined to the gland). (B) PTC were divided into those with aggressive features (invasion, metastasis, recurrence, and persistence) and those with indolent features (confined to the gland). The average IGF-I-R staining intensity was compared by ANOVA.

Table 2. Childhood thyroid cancers stratified according to IGF-I

\begin{tabular}{|c|c|c|c|}
\hline & $\begin{array}{c}\text { IGF-I }(+) \\
(n=13)\end{array}$ & $\begin{array}{c}\text { IGF-I (-) } \\
(n=16)\end{array}$ & $p$ \\
\hline Gender (M/F) & $2 / 10$ & $3 / 12$ & 0.83 \\
\hline Unknown & 1 & 1 & \\
\hline Patient age $(y)^{1}$ & $15.3 \pm 1.50$ & $17.2 \pm 0.84$ & 0.27 \\
\hline Tumor size $(\mathrm{cm})^{1}$ & $2.07 \pm 0.45$ & $2.05 \pm 0.44$ & 0.98 \\
\hline MACIS score ${ }^{1,2}$ & $4.20 \pm 0.44$ & $3.71 \pm 0.14$ & 0.22 \\
\hline \multicolumn{4}{|l|}{ Class $^{3}$} \\
\hline 1 & 4 & 8 & 0.35 \\
\hline 2 & 3 & 6 & \\
\hline 3 & 1 & 0 & \\
\hline 4 & 1 & 0 & \\
\hline Unknown & 4 & 2 & \\
\hline Unifocal/multifocal & $6 / 6$ & $8 / 7$ & 0.87 \\
\hline Unknown & 1 & 1 & \\
\hline \multicolumn{4}{|l|}{ Surgery ${ }^{4}$} \\
\hline Total thyroidectomy & 6 & 14 & 0.12 \\
\hline Subtotal thyroidectomy & 4 & 1 & \\
\hline Lobectomy & 0 & 0 & \\
\hline Unknown & 3 & 1 & \\
\hline \multicolumn{4}{|l|}{ Radioactive iodine therapy } \\
\hline Yes/no & $7 / 1$ & $10 / 2$ & 0.80 \\
\hline Unknown & 5 & 4 & \\
\hline Follow-up (mo) ${ }^{1}$ & $58.5 \pm 16.1$ & $55.6 \pm 8.8$ & 0.87 \\
\hline Time to recur $(\mathrm{mo})^{1}$ & $10.7 \pm 3.3$ & $30 \pm 18.5$ & 0.36 \\
\hline IGF-I-R expression $^{1}$ & $0.71 \pm 0.29$ & $0.38 \pm 0.13$ & 0.21 \\
\hline
\end{tabular}

\footnotetext{
${ }^{1}$ Data represent mean \pm SEM.

${ }^{2}$ MACIS score as defined by Hay et al. 17.

${ }^{3}$ Class according to DeGroot et al. 12 .

${ }^{4}$ Surgery includes procedures referred to as "completion thyroidectomy."
}

which expressed IGF-I-R. The overall risk of recurrence was significantly greater for all tumors (PTC and FTC) that expressed IGF-I-R ( $p=0.05$ by Fisher's Exact Test) and for all PTC that expressed IGF-I-R (4/16 indolent and 5/6 aggressive PTC expressed IGF-I-R, $p=0.023)$. However, when diseasefree survival was determined (Fig. 4), the difference only approached statistical significance $(p=0.08)$.

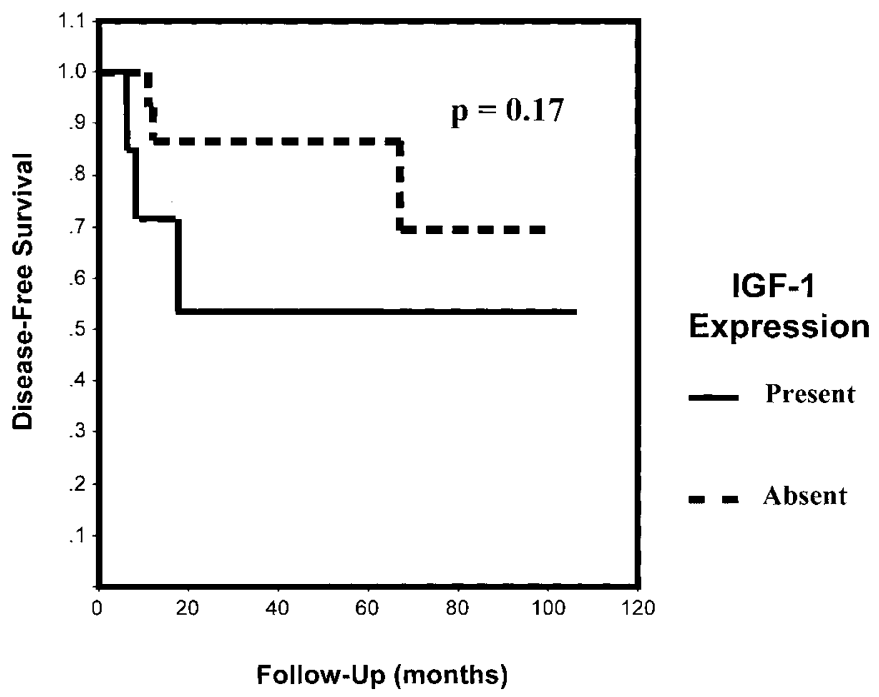

Figure 3. Disease-free survival for thyroid cancers stratified by IGF-I expression. Thyroid cancers were divided into those that expressed IGF-I and those that did not. Disease-free survival was calculated by Kaplan-Meier survival analysis and log-rank comparison.

\section{DISCUSSION}

Expression of IGF and IGF-I-R has been detected in a variety of cancers and linked to tumor growth and prognosis $(1-6,8-10,13-15)$. Several of these studies indicate that IGF-I-R expression is critical not only for transformation, but for aggressive behavior as well $(7,11)$.

Thyroid cancers have also been shown to express IGF and IGF-I-R, but the clinical impact is not entirely clear. IGF-I was expressed by the majority of adult PTC, but there was no impact associated with IGF-I expression on clinical outcome (8-10). IGF-I-R expression correlated with tumor size in adults, suggesting that IGF-I-R might be associated with a poor prognosis (11). However, IGF-I-R were only expressed by 
Table 3. Childhood thyroid cancers stratified according to IGF-I-R

\begin{tabular}{|c|c|c|c|}
\hline & $\begin{array}{c}\text { IGF-I-R }(+) \\
(n=10)\end{array}$ & $\begin{array}{c}\text { IGF-I-R }(-) \\
(n=13)\end{array}$ & $p$ \\
\hline Gender $(\mathrm{M} / \mathrm{F})$ & $2 / 8$ & $2 / 10$ & 0.84 \\
\hline Unknown & 0 & 1 & \\
\hline Patient age $(y)^{1}$ & $18.0 \pm 0.88$ & $15.4 \pm 1.31$ & 0.13 \\
\hline Tumor size $(\mathrm{cm})^{1}$ & $1.51 \pm 0.26$ & $2.31 \pm 0.57$ & 0.25 \\
\hline MACIS score ${ }^{1,2}$ & $3.70 \pm 0.16$ & $4.06 \pm 0.38$ & 0.45 \\
\hline \multicolumn{4}{|l|}{ Class $^{3}$} \\
\hline 1 & 3 & 6 & 0.48 \\
\hline 2 & 4 & 4 & \\
\hline 3 & 1 & 0 & \\
\hline 4 & 0 & 1 & \\
\hline Unknown & 2 & 2 & \\
\hline Unifocal/multifocal & $4 / 6$ & $6 / 6$ & 0.69 \\
\hline Unknown & & 1 & \\
\hline \multicolumn{4}{|l|}{ Surgery $^{4}$} \\
\hline Total thyroidectomy & 9 & 9 & 0.48 \\
\hline Subtotal thyroidectomy & 0 & 2 & \\
\hline Lobectomy & 0 & 0 & \\
\hline Unknown & 1 & 2 & \\
\hline \multicolumn{4}{|l|}{ Radioactive iodine therapy } \\
\hline Yes/no & $8 / 0$ & $8 / 2$ & 0.48 \\
\hline Unknown & 2 & 3 & \\
\hline Follow-up (mo) ${ }^{1}$ & $76.7 \pm 8.5$ & $43.9 \pm 13.4$ & 0.06 \\
\hline Time to recur $(\mathrm{mo})^{1}$ & $23.2 \pm 11.0$ & 6 & \\
\hline IGF-I expression $^{1}$ & $0.7 \pm 0.34$ & $0.38 \pm 0.21$ & 0.42 \\
\hline
\end{tabular}

${ }^{1}$ Data represent mean \pm SEM.

${ }^{2}$ MACIS score as defined by Hay et al. 17.

${ }^{3}$ Class according to DeGroot et al. 12 .

${ }^{4}$ Surgery includes procedures referred to as "completion thyroidectomy."

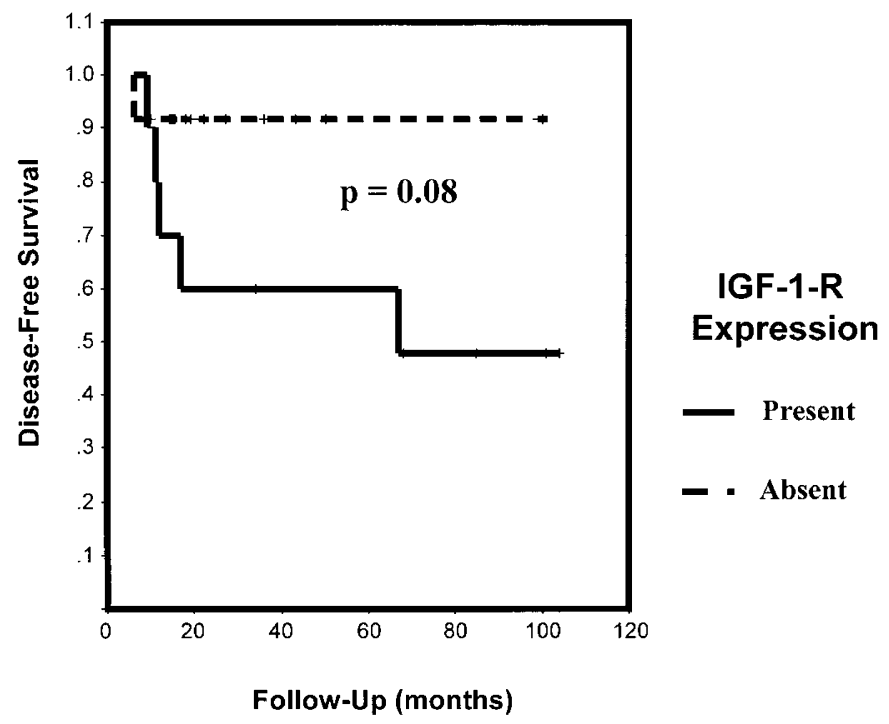

Figure 4. Disease-free survival for thyroid cancers stratified by IGF-I-R expression. Thyroid cancers were divided into those that expressed IGF-I-R and those that did not. Disease-free survival was calculated by Kaplan-Meier survival analysis and log-rank comparison.

differentiated thyroid cancers and not poorly differentiated thyroid cancers, suggesting the prognosis for IGF-I-R expressing tumors would be more favorable (13-15). In addition, none of these studies included any childhood thyroid cancers, which tend to be well-differentiated and to have a favorable prognosis (16). To our knowledge, no previous study has examined these questions in childhood thyroid tumors.
Our data show that IGF-I and IGF-I-R are expressed by some childhood thyroid cancers, including both PTC and FTC histologic variants. Neither IGF-I nor IGF-I-R was detected in any of the normal thyroid sections in our study, suggesting either that IGF-I and IGF-I-R expression are limited to neoplastic diseases of the thyroid, or that the intensity of expression in normal thyroid is below the level of sensitivity for immunostaining. These data are consistent with those of Silva Filho et al. (8), who showed that more than $90 \%$ of adult PTC express IGF-I. Also, like Silva Filho et al., we found that the expression of IGF-I had no impact on the clinical course of childhood thyroid cancers. The expression of IGF-I was similar in aggressive and indolent thyroid tumors, and disease-free survival, although somewhat reduced in IGF-I expressing tumors, was not significantly different. Despite these facts, the prognosis for children with thyroid cancer is generally more favorable than for adults (16). It is interesting that a higher proportion of adult thyroid cancers $(90 \%)$ were found to express IGF-I compared with our results in children (39\%) (8-10). Based on this comparison, it is possible that IGF-I might still have a role in the more aggressive behavior of adult thyroid cancers.

Previous studies have shown that disease-free survival for children with PTC is similar to that of children with FTC (16). Based on this similarity, we then compared aggressive tumors (PTC and FTC with invasion, metastasis, recurrent, or persistent disease as well as aggressive PTC alone) with indolent tumors (PTC and FTC confined to the gland, as well as indolent PTC alone) and found that aggressive tumors had more intense expression of IGF-I-R than indolent tumors $(p=$ $0.029)$ and that aggressive PTC had more intense IGF-I-R expression than indolent PTC $(p=0.029)$. We also found that the overall risk of recurrence was increased for IGF-I-R expressing tumors (PTC and FTC together, $p=0.05$; PTC alone, $p=0.023)$. This is consistent with the important role for IGF-I-R proposed by Sell et al. (7) and suggests that the expression of IGF-I-R might be important in supporting invasion, metastasis, and recurrence of thyroid cancers in children. Unfortunately, our recurrence data could be biased by the longer follow-up provided to patients with tumors that expressed IGF-I-R ( $77 \pm 8.5$ versus $43.9 \pm 13.4 \mathrm{mo}, p=0.06)$. This would have allowed for more recurrent disease to be detected. Consistent with this limitation, disease-free survival, although shorter for patients with thyroid cancers that expressed IGF-I-R, only approached statistical significance ( $p=$ 0.08 ). Because of this limitation, additional studies from other investigators will need to be performed to confirm or refute this observation.

We did not find any significant correlation between IGF-I-R and tumor size. In a previous study of adult thyroid cancers, Maiorano et al. (11) found that IGF-I-R was expressed by the majority of thyroid cancers and significantly correlated with tumor size. The reasons for this difference are not entirely clear. Recent observations in adult thyroid cancers indicate that hybrid receptors can be formed between IGF-I-R and the IR (13-15). These hybrid receptors would confer the ability to bind IGF-II and might be important in tumor growth (1). Unfortunately, our current report does not examine IGF-II 
expression, preventing us from addressing this possibility. It is also possible that IGF-I-R might not have as important a role in thyroid cancer growth during childhood. We previously found that VEGF expression is closely related to the size and recurrence risk for thyroid cancers in adults and children (19, 20). It is possible that other growth factors such as VEGF might have more control over the growth of childhood thyroid cancers.

We did not observe any difference in IGF-I or IGF-I-R expression between PTC and FTC. This is consistent with our previous finding that, unlike in adults, disease-free survival for children with PTC and FTC is similar (16). We also failed to find any correlation between the intensity of IGF-I or IGF-I-R expression and that of VEGF, which was previously shown to correlate with recurrence risk $(19,20)$. There are many possible explanations for this, but we believe it possible that any growth factor (VEGF, IGF-I, IGF-II, etc.) might be sufficient to support thyroid cancer growth and metastasis (8-10, 19-21). If so, an individual tumor would not need to make all these growth factors to show aggressive clinical behavior. Unfortunately, this would also preclude reliance on only one growth factor to prospectively identify patients with the highest risk of recurrence.

We should emphasize that our findings are limited by the small number of samples and the retrospective nature of the clinical data (16). The number of recurrent PTC in our study was small $(n=6)$, limiting the power of our statistical analyses. Nonetheless, thyroid cancers are unusual during childhood and these data represent one of the largest collections of childhood thyroid tumors (16). The data support the hypothesis that expression of IGF-I-R by childhood thyroid cancers is associated with less favorable outcomes.

Due to the retrospective nature of our data collection, patients received their care over several decades, most of which were before the routine use of serum $\mathrm{Tg}$ measurements for the detection of recurrent or persistent disease. For this reason, we are unable to correlate serum $\mathrm{Tg}$ values with the presence or absence of IGF-I or IGF-I-R expression. Although some of these historical patients might have had detectable serum Tg and would therefore have been incorrectly identified as free of disease, the treatment of such ${ }^{131}$ Iodine scan-negative, Tgpositive patients is controversial (22). Furthermore, in all of our contemporary patients classified as free of disease $(n=5)$, serum $\mathrm{Tg}$ values were $<10 \mathrm{ng} / \mathrm{mL}$ (normal, $3-40 \mathrm{ng} / \mathrm{mL}$ ). The magnitude of serum $\mathrm{Tg}$ values that indicate freedom from disease has been debated but is recently believed to be $<2$ $\mathrm{ng} / \mathrm{mL}$ (23). Previous studies that span the period of our observations suggested that levels might be as high as 10 $\mathrm{ng} / \mathrm{mL}(24,25)$. It is possible that some of our patients might develop recurrent disease as they are followed for a longer period of time.

In conclusion, the current study has shown that differentiated thyroid cancers of children and adolescents, including PTC and FTC, express IGF-I and the IGF-I-R. Tumors that express IGF-I-R are more likely to show aggressive clinical features such as invasion beyond the thyroid capsule and metastasis. They are also more likely to recur and persist despite treatment.

\section{REFERENCES}

1. Toropainen E, Lipponen P, Syrjanen K 1995 Expression of insulin-like growth factor I (IGF-I) in female breast cancer as related to established prognostic factors and long-term prognosis. Eur J Cancer 9:1443-1448

2. Fukuda I, Hizuka N, Murakami Y, Itoh E, Yasumoto K, Sata A, Takano K 2001 Clinical features and therapeutic outcomes of 65 patients with acromegaly at Tokyo Women's Medical University. Intern Med 40:987-992

3. Weber MM, Fottner C, Liu SB, Jung MC, Engelhardt D, Baretton GB 2002 Overexpression of the insulin-like growth factor I receptor in human colon carcinomas. Cancer 95:2086-2095

4. Kelly RG, Nally K, Shanahan F, O'Connell J 2002 Type I insulin-like growth factor receptor expression on colorectal adenocarcinoma cell lines is decreased in response to the chemopreventive agent $N$-acetyl-L-cysteine. Ann N Y Acad Sci 973:555-558

5. Reinmuth N, Fan F, Liu W, Parikh AA, Stoeltzing O, Jung YD, Bucana CD, Radinsky R, Gallick GE, Ellis LM 2002 Impact of insulin-like growth factor receptor-I function on angiogenesis, growth, and metastasis of colon cancer. Lab Invest 82:1377-1389

6. Guo N, Ye JJ, Liang SJ, Mineo R, Li SL, Giannini S, Plymate SR, Sikes RA, Fujita-Yamaguchi Y 2003 The role of insulin-like growth factor-II in cancer growth and progression evidenced by the use of ribozymes and prostate cancer progression models. Growth Horm IGF Res 13:44-53

7. Sell C, Dumenil G, Deveaud C, Miura M, Coppola D, DeAngelis T, Rubin R, Efstratiadis A, Baserga R 1994 Effect of a null mutation of the insulin-like growth factor I receptor gene on growth and transformation of mouse embryo fibroblasts. Mol Cell Biol 14:3604-3612

8. Silva Filho GB, Maciel RM, Takahashi MH, Alberti VN, Castro IV, Saldiva PH, Durazzo MD, Ferraz AR 1999 Study of immunohistochemical expression of insulinlike growth factor I and proliferating cell nuclear antigen in thyroid gland papillary carcinoma and its metastasis. Head Neck 21:723-727

9. Onoda N, Ohmura E, Tsushima T, Ohba Y, Emoto N, Isozaki O, Sato Y, Shizume K, Demura H 1992 Autocrine role of insulin-like growth factor (IGF)-I in a human thyroid cancer cell line. Eur J Cancer 11:1904-1909

10. Yashiro T, Ohba Y, Murakami H, Obara T, Tsushima T, Fujimoto Y, Shizume K, Ito K 1989 Expression of insulin-like growth factor receptors in primary human thyroid neoplasms. Acta Endocrinol 121:112-120

11. Maiorano E, Ciampolillo A, Viale G, Maisonneuve P, Ambrosi A, Triggiani V, Marra E, Perlino E 2000 Insulin-like growth factor 1 expression in thyroid tumors. Appl Immunohistochem Mol Morphol 8:110-119

12. DeGroot LJ, Kaplan EL, McCormick M, Straus FH 1990 Natural history, treatment, and course of papillary thyroid carcinoma. J Clin Endocrinol Metab 71:414-424

13. Belfiore A, Pandini G, Vella V, Squatrito S, Vigneri R 1999 Insulin/IGF-I hybrid receptors play a major role in IGF-I signaling in thyroid cancer. Biochimie 81:403407

14. Vella V, Sciacca L, Pandini G, Mineo R, Squatrito S, Vigneri R, Belfiore A 2001 The IGF system in thyroid cancer: new concepts. Mol Pathol 54:121-124

15. Vella V, Pandini G, Sciacca L, Mineo R, Vigneri R, Pezzino V, Belfiore A 2002 A novel autocrine loop involving IGF-II and the insulin receptor isoform-A stimulates growth of thyroid cancer. J Clin Endocrinol Metab 87:245-254

16. Welch Dinauer CA, Tuttle RM, Robie DK, McClellan DR, Svec RL, Adair C, Francis GL 1998 Clinical features associated with metastasis and recurrence of differentiated thyroid cancer in children, adolescents and young adults. Clin Endocrinol 49:619-628

17. Hay ID, Bergstralh EJ, Goellner JR, Ebersold JR, Grant CS 1993 Predicting outcome in papillary thyroid carcinoma: development of a reliable prognostic scoring system in a cohort of 1779 patients surgically treated at one institution during 1940 through 1989. Surgery 114:1050-1057

18. Gupta S, Patel A, Folstad A, Fenton C, Dinauer CA, Tuttle RM, Conran R, Francis GL 2001 Infiltration of differentiated thyroid carcinoma by proliferating lymphocytes is associated with improved disease-free survival for children and young adults. J Clin Endocrinol Metab 86:1346-1354

19. Fenton C, Patel A, Dinauer C, Robie DK, Tuttle RM, Francis GL 2000 The expression of vascular endothelial growth factor and the type 1 vascular endothelial growth factor receptor correlate with the size of papillary thyroid carcinoma in children and young adults. Thyroid 10:349-357

20. Lennard CM, Patel A, Wilson J, Reinhardt B, Tuman C, Fenton C, Blair E, Francis GL, Tuttle RM 2001 Intensity of vascular endothelial growth factor expression is associated with increased risk of recurrence and decreased disease-free survival in papillary thyroid cancer. Surgery 129:552-558

21. Ramirez R, Hsu D, Patel A, Fenton C, Dinauer C, Tuttle RM, Francis GL 2000 Over-expression of hepatocyte growth factor/scatter factor (HGF/SF) and the HGF/SF receptor (cMET) are associated with a high risk of metastasis and recurrence for children and young adults with papillary thyroid carcinoma. Clin Endocrinol 53:635644

22. Wartofsky L 2000 An approach to the management of patients with scan negative, thyroglobulin positive, differentiated thyroid cancer: alternative imaging procedures. In: Wartofsky L (ed) Thyroid Cancer: A Comprehensive Guide to Clinical Management. Humana Press, Totowa NJ, pp 251-262

23. Mazzaferri EL, Kloos RT 2002 Is diagnostic iodine-131 scanning with recombinant human TSH useful in the follow-up of differentiated thyroid cancer after thyroid ablation? J Clin Endocrinol Metab 87:1490-1498

24. Cailleux AF, Baudin E, Travagli JP, Ricard M, Schlumberger M 2000 Is diagnostic iodine-131 scanning useful after total thyroid ablation for differentiated thyroid cancer? J Clin Endocrinol Metab 85:175-178

25. Hung W, Sarlis NJ 2002 Current controversies in the management of pediatric patients with well-differentiated nonmedullary thyroid cancer: a review. Thyroid 12:683-702 